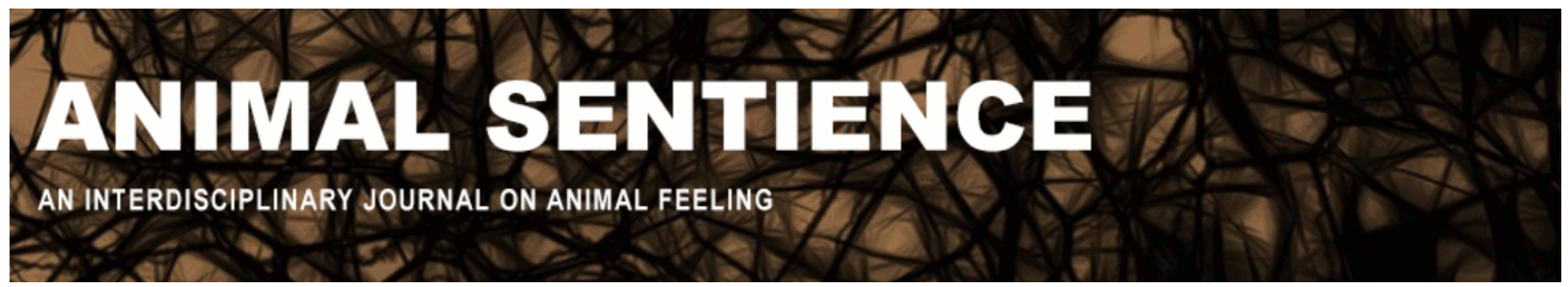

Phalke, Sagarika (2020) Rewilding elephants: A solution or a potential problem?. Animal Sentience 28(15)

DOI: $10.51291 / 2377-7478.1575$

Date of submission: 2020-04-13

Date of acceptance: 2020-04-23

(c) (†)

This article has appeared in the journal Animal

Sentience, a peer-reviewed journal on animal

cognition and feeling. It has been made open access,

free for all, by WellBeing International and deposited

in the WBI Studies Repository. For more information,

please contact

wbisr-info@wellbeingintl.org.

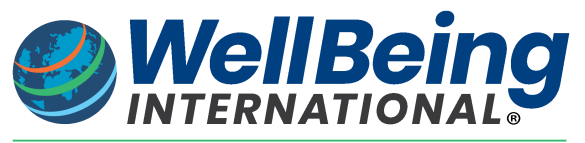

SOLUTIONS FOR PEOPLE, ANIMALS AND ENVIRONMENT 


\title{
Rewilding elephants: A solution or a potential problem?
}

Commentary on Baker \& Winkler on Elephant Rewilding

\author{
Sagarika Phalke \\ School of Biological Sciences, The University of Hong Kong
}

\begin{abstract}
Baker \& Winkler (B\&W) provide a comprehensive and systematic review of Thailand's captive tourist elephants. They propose rewilding as a solution to improving the welfare of captive tourist elephants. They also advocate this method for restoring degraded forests, elephant conservation and preserving traditional elephant-keeping practices and knowledge. This commentary argues that rewilding might exacerbate negative humanelephant interactions and impede conservation efforts. While further research is required for rewilding to be considered a viable and practical solution, B\&W's focus on documenting traditional knowledge which can directly contribute to the welfare of captive elephants remains important.
\end{abstract}

\begin{abstract}
Sagarika Phalke has studied conditions of captive elephants within the Asian context. With an MSc. in Human-Animal Interactions from the University of Stirling (UK) and practical work experience in South Asia, her focus is on applied research in the field. Website
\end{abstract}

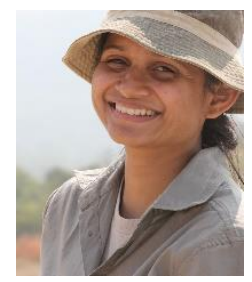

Introduction. Baker \& Winkler's (2020) target article (B\&W) provides a comprehensive and systematic review of Thailand's captive tourist elephants. Their proposal for rewild ling aims to improve the welfare conditions of elephants in captivity. It is also supposed to restore degraded forests, aid in elephant conservation and promote and preserve traditional elephant-keeping practices. The detailed and nuanced approach to human-elephant interaction that $\mathrm{B} \& \mathrm{~W}$ suggest is important, as this is a critical concern in managing elephants in captivity and has to be addressed to improve welfare. However, for rewilding of captive elephants to be considered a viable and practical solution for welfare and conservation, the approach requires further research and thought in an Asian context.

Improving welfare or producing conflicts of interest? The greatest current threat to the conservation of Asian elephants is human-elephant interaction over agriculture and forestry. While the target article has looked at the concept of human-elephant interactions with a focus on the mahouts, it has not looked at the impact rewilding might have on local communities who depend on agriculture for their livelihoods. Asia contains some of the fastest growing countries in terms of economic growth and human densities, with Thailand's population ranking $4^{\text {th }}$ in southeast Asia (United Nations, 2019). Much of this population lives in rural areas and depends on agricultural and livestock farming. Competing resources and diminishing spaces put humans into direct contact with elephants (Shaffer et al., 2019). In his commentary, McGrew (2020) asks whether rewilded elephants pose a risk to humans and create conflicts over resources. Previous rewilding attempts in Thailand have indicated that this is the case. Angkavanish \& Thitaram (2012) found that some rewilded elephants foraged on crops to the detriment of the people. Livestock owners and villagers dependent on non-timber forest 
products were also affected by elephants introduced in the park. Although there were no retaliatory killings of elephants recorded in that study, the authors state that this cannot be guaranteed in the future. There is a real risk of rewilding exacerbating hostile human-elephant interactions, leading to a dilution of welfare and conservation efforts rather than support.

Effects on the ecosystem through space and time. B\&W suggest that rewilding elephants offers an ecologically viable alternative in bringing back historical forest lands destroyed by large-scale agriculture. Elephants provide a critical ecological role in maintaining tree diversity through seed-dispersal (Campos-Arceiz \& Blake, 2011) and are often referred to as ecosystem engineers because of their impact on their habitats (Fritz, 2017). They are found to disperse seeds across long distances (Campos-Arceiz et al., 2008), and their seasonal movement patterns alter forest ecosystems. Whereas $B \& W$ suggest that there are positive effects of elephants in restoring degraded habitats, elephants are also known to be destructive foragers causing loss of tree density and richness (Frizt, 2017; Rutina \& Moe, 2014; Duffy et al., 2002). Given that only $32 \%$ of the forest in Thailand appears to be suitable elephant habitat (Baker \& Winkler, 2020; Permsirivanchai, 2017), the impact of releasing high densities of elephants into fragmented habitats needs to be carefully considered.

Other factors can influence the movement of captive elephants and the spatial use of forests such as behavioural characteristics of elephants (Duffy et al., 2002), and group dominance hierarchies (Leighty et al., 2010). Although I am in agreement with B\&W that captive elephants cannot be considered domesticated and still maintain some of their wild traits, it would be premature to discount the effect of captivity on their behaviour. Before releasing captive elephants into the wild, there are certain aspects which require more comprehensive examination. How do rehabilitated elephants use the habitat? Would we see seasonal movement in their behaviour, or would they cluster themselves to a particular location causing habitat loss rather than restoration? Would factors such as personality, individual traits, and grouping structures affect elephant movement and also forest degradation?

Traditional elephant knowledge and captive welfare. Although there are unresolved concerns with the concept of rewilding, B\&W have highlighted the critical element of mahoutelephant interactions and their impact on welfare. More inexperienced mahouts with no knowledge of elephant behaviour are joining the profession; this could have grave consequences for both nonhuman animals and humans. The system of elephant handling is changing across Asia. It was once a family profession, with the knowledge of elephant-handling being passed down through successive generations. Mahouts don't want their children to enter the profession (personal observation). Factors such as working with a potentially dangerous animal, alcoholism, low salaries and poor quality of life influence this opinion. The cumulative traditional knowledge of elephant keeping is at the risk of being lost. Historic knowledge of elephant behaviour and physiology urgently needs to be recorded and systematically documented. This could help us in improving captive elephant welfare through the marriage of the old with the new. Using the expertise of the older mahouts, training modules blending traditional knowledge with current practices of positive reinforcement can be created for new mahouts entering this profession. A more systematic, applied and intentional use of traditional knowledge can lead to better welfare of elephants and safer practices for mahouts. 
Conclusion. B\&W define rewilding as "a state of being wild that is meaningful to elephants". I understand and agree with the authors' intentions in providing an environment in which captive elephants have the opportunity to engage in natural behaviours. However, will rewilded elephants behave like their wild-counterparts and use forests as we expect them to? If the concept of "meaningful" is to improve the welfare of captive elephants by providing a natural environment, there may be other more immediate and workable solutions. Across Asia a large majority of elephants are maintained under the extensive systems of management. Here elephants are let out into adjoining forests at night where they can engage in natural behaviours and interact with wild conspecifics. Whereas elephants remain under human control, its influence is diminished and they have freedom of choice (preferred associates, movement, foraging). As Lee \& Baker (2020) suggest, this system could help ameliorate current welfare standards. Extensive systems of management have had a positive influence on various aspects of welfare (Phalke et al., forthcoming) and could foster a life worth living for captive elephants.

\section{References}

Angkavanish, T., \& Thitaram, C. (2012). Behavioral study and monitoring of Asian elephant (Elephas maximus) reintroduction under the Queen's initiative. In Elephants: ecology, behavior and conservation. New York: Nova Science Publishers, 133-144.

Baker, L., \& Winkler, R. (2020). Asian elephant rescue, rehabilitation and rewilding. Animal Sentience 28(1).

Campos-Arceiz, A., \& Blake, S. (2011). Megagardeners of the forest-the role of elephants in seed dispersal. Acta Oecologica, 37(6), 542-553.

Campos-Arceiz, A., Larrinaga, A. R., Weerasinghe, U. R., Takatsuki, S., Pastorini, J., Leimgruber, P., Fernando, P., \& Santamaría, L. (2008). Behavior rather than diet mediates seasonal differences in seed dispersal by Asian elephants. Ecology, 89(10), 2684-2691.

Duffy, K. J., Van Os, R., Vos, S., Van Aarde, J., Ellish, G., \& Stretch, A. B. (2002). Estimating impact of reintroduced elephant on trees in a small reserve. South African Journal of Wildlife Research, 32(1), 23-29.

Fritz, H. (2017). Long-term field studies of elephants: understanding the ecology and conservation of a long-lived ecosystem engineer. Journal of Mammalogy, 98(3), 603-611.

Lee, P.C., \& Lindsay, W.K. (2020). A "halfway house" for improving captive welfare. Animal Sentience 28(14).

Leighty, K. A., Soltis, J., \& Savage, A. (2010). GPS assessment of the use of exhibit space and resources by African elephants (Loxodonta africana). Zoo Biology, 29(2), 210-220.

McGrew, W. C. (2020). Practicalities of rewilding. Animal Sentience 28(9).

Permsirivanchai, J. (2017). Forest area of Thailand, 1973-2016. Forest Land Management Bureau, Royal Forestry Department of Thailand.

Rutina, L. P., \& Moe, S. R. (2014). Elephant (Loxodonta africana) disturbance to riparian woodland: effects on tree-species richness, diversity and functional redundancy. Ecosystems, 17(8), 13841396.

Shaffer, L. J., Khadka, K. K., Van Den Hoek, J., \& Naithani, K. J. (2019). Human-elephant conflict: a review of current management strategies and future directions. Frontiers in Ecology and Evolution, 6, 235.

United Nations. (2019). World population prospects 2019. Department of Economic and Social Affairs. 


\section{Call for Papers}

Special Issue of the Journal of Consciousness Studies

Plant Sentience: Theoretical and Empirical Issues

Guest Editors: Vicente Raja (Rotman Institute of Philosophy, Western University) Miguel Segundo-Ortin (School of Liberal Arts, University of Wollongong)

In this special issue, we address the issue of plant sentience/consciousness from different disciplines that combine both theoretical and empirical perspectives. Some of the questions to be addressed in the special issue include the following:

- Plants exhibit interesting behaviors; does this entail that they are conscious to some extent?

- What are the requirements for a living organism to be conscious? Do plants meet these requirements?

- What does the possibility of plant sentience/consciousness entail for the study of the evolution of consciousness?

- Is it just a categorical mistake to attribute consciousness to plants?

- Can we talk about different levels or degrees of consciousness?

\section{How to submit?}

\section{Deadline: June 1st, 2020}

Please submit your papers (max. 9000 words including footnotes, references, abstract, etc.) to vgalian@uwo.ca with subject "Paper Special Issue JCS".

For more information, including bibliography and more detailed descriptions of the topics and questions to be addressed in the papers submitted to the special issue, please contact the guest editors at vgalian@uwo.ca (Vicente) or mso693@uowmail.edu.au (Miguel). 